\title{
Ethical Marketing: Perceptions of Economic Goods and Social Problems
}

\author{
Gene R. Laczniak, Robert F. Lusch, and William A. Strang
}

\begin{abstract}
A methodology associated with experimental social psychology was used to ascertain whether there are different ethical overtones perceived in the marketing of different products despite all other aspects of the marketing situation being comparable. The methodology consisted of using four vignettes of marketing strategy with the product utilized being the only element varied across the scenarios. Results indicate that ethical evaluations are product dependent and are more severe for social goods than for traditional economic goods.
\end{abstract}

The issue of ethics in the practice of marketing has been the subject of substantial debate over the years (Clausen 1967; Calihan 1967; Andreason 1977). The ethics of marketing efforts have been questioned in at least two distinct areas (Greenland 1974; Hise 1975). First, the process of marketing has sometimes been perceived as unethical and second, the product being marketed has sometimes been perceived as unethical. Process related issues involve the unethical use of marketing strategies or tactics (eg., deceptive advertising of "bait and switch" selling or "push money" to middlemen). For instance, it is perfectly proper for a major brewer to seek distribution of its product in a new metropolitan hotel. However, if the brewer attempts to influence the adoption decision by purchasing new golf clubs for the top managers of the hotel, the process of marketing in this case becomes subject to ethical and legal scrutiny.

Product related issues involve the ethical appropriateness of marketing certain products (e.g., cigarettes, intimate personal hygiene items, or sugar-coated cereals). Product related issues have led to the banning of TV commercials for cigarettes, restrictions regarding liquor and contraceptive promotions and the current debate over the propriety of advertising breakfast cereals and toys to children. In these latter situations, the public often seems to object predominantly to the product being promoted rather than to the impropriety of the marketing campaign. For example, segments of the public are not particularly bothered by seeing the "Marlboro Man" in a TV commercial; rather

Gene R. Laczniak is an Associate Professor of Business at Marquette University. Robert F. Lusch is an Associate Professor of Business at the University of Oklahoma. William A. Strang is a Professor of Business at the University of Wisconsin-Madison. they question whether it is proper that a cancer causing product such as cigarettes should be promoted in a forum with the broad exposure of TV. Put another way, one can create an ethical TV ad for cigarettes, but it is the product itself that should possibly be banned or restricted because (in the opinion of some) it is inherently unethical.

Product issues are likely to become more important as the scope of marketing continues to broaden. Marketing methods are increasingly being applied in nonprofit organizations such as arts companies, hospitals and universities (Kotler and Levy 1969; Kotler 1975; Gaedeke 1977). Some social critics are likely to question the use of marketing in these nontraditional areas. One of the most intriguing aspects of the broadened marketing is labeled social marketing. Social marketing has been defined as "the design, implementation and control of programs calculated to influence the acceptability of social ideas and involving considerations of product planning, pricing, communication, distribution and marketing research" (Kotler and Zaltman 1971, p. 5). Efforts to "market" political candidates and their platforms, encourage birth control, conserve energy or discourage cigarette smoking are familiar examples of social marketing (Kotler 1975; Gaedeke 1977). Recently, some ethical questions regarding the widespread use of social marketing have been raised (Laczniak, Lusch, and Murphy 1979). One of the most troublesome ethical issues revolves around the inherently controversial nature of many social issues which could potentially be marketed such as homosexual rights, abortion, pornographic entertainment, etc. Social "products" such as these are likely to raise ethical issues when they are systematically promoted.

Naturally, there are some social issues, such as auto safety and conservation, that seldom raise ethical questions when they are marketed. Nevertheless, if people, when 
making their ethical evaluations of marketers, are strongly influenced by the nature of the products or issues promoted, independent of the marketing process used, then the continual broadening of marketing is likely to create an inordinate amount of public criticism of marketing. We believe this development is fairly predictable, given our observance of what has occurred with ethically charged traditional economic goods (i.e., restrictions upon the marketing of liquor and cigarettes). Further, another underlying problem is that people find it difficult to separate the ethics of the marketing process from ethical implications of the product or issue being marketed. Therefore, the purpose of this paper is to provide some initial empirical evidence regarding the degree to which a select group of individuals are influenced in their ethical evaluations of marketing by the type of product being marketed and whether they distinguish the ethical ramifications of the marketing process from the product involved.

\section{- METHODOLOGY}

The application of empirical methods to ethical issues-other than surveying personal values and opinionsis not very common. The notion that consumers often object to the product being marketed rather than to how the product is marketed (i.e., the process) makes intuitive sense but, not surprisingly, has never been systematically examined. Direct questioning of consumers on this issue would probably produce unreliable and biased results since the issue being considered is conceptually difficult to grasp. In short, if the public was surveyed on this issue, each respondent would react based upon a different mental picture of the situation. Considering that very few respondents would conjure up the same mental picture, the results would likely be tainted. In other words, asking the public if they have any ethical objections to a product or ethical objections to the process in which a product is marketed, is simply too difficult an inquiry.

This research problem is not unique to this situation, but is frequently encountered in the behavioral sciences when opinion or attitude surveys are used to investigate abstract issues or ideas. For example, abstract issues such as "democracy" and "brotherhood" are difficult to assess because of the varying perceptions people have of these concepts. The "vignette" technique has been developed in experimental social psychology to overcome this problem (Alexander and Becker 1978; Nosanchuck 1972; Rossi, Simpson, and Bose 1974). This technique involves presenting the respondents with a detailed and concrete stimulus which embodies the concept under investigation in the form of a vignette. For instance, a series of short descriptions of how democracy might be applied in a community or municipal setting, would be authored. By systematically varying certain elements of the vignette, the researcher can analyze the impact of changes in the stimulus on the responses. For instance, how does the public react to different forms of democracy? Do they react differently to small-town democracy versus large-city democracy? Also, the vignette method allows the concept being evaluated to "more closely approximate a real-life decision-making or judgment-making situation. Furthermore, by holding the stimulus constant over a heterogeneous respondent population, the survey researcher gains a degree of uniformity and control over the stimulus situation approximating that achieved by researchers using experimental designs" (Alexander and Becker 1978, p. 93). Utilization of such a vignette technique allowed the authors to test whether individuals are influenced in their ethical evaluations of marketing by the product being marketed or by the marketing technique (process). Four "products" perceived by the authors as having different ethical propriety in the mind of the public were selected. The products were: a drug education program, a dishwasher, a hot lather machine, and a political candidate. The authors selected two economic products (dishwasher and hot lather machine) and two social products (political candidate and drug education program) in order to provide a reasonably wide range of marketing situations. The authors initially believed that marketing the dishwasher and drug education program would be perceived as having positive or neutral ethical connotations, whereas, marketing the hot lather machine (because it was trivial and energy wasteful) and the political candidate (because of the potential social consequences of political manipulation) would be perceived as more ethically questionable. Obviously, the author's subjective beliefs about these products were not mentioned in the vignettes.

To provide a test of our proposition, the marketing of each of the four products was depicted in a descriptive and nearly identical vignette that purposefully emphasized the potential "power" of a marketing campaign. This was accomplished by setting the vignettes in the future (specifically, the year 1998) at a time when marketing techniques were portrayed as virtually assuring the success of a product. Each respondent was exposed to only one vignette to eliminate the testing effect. Emphasis on the power of marketing techniques provided respondents with every possible opportunity to object to the ethical appropriateness of marketing all the products involved. In other words, by creating the descriptions in a manner which highlighted the ability of marketing techniques to produce "success," the authors hoped to maximize the likelihood that respondents might question the ethical dimensions of the marketing process rather than the product involved. The vignettes were quite detailed running about 1000 words in length. The four vignettes (one for each product) were written to be parallel and consistent except, of course, for the product involved. (At this time the reader should please carefully review the two sample vignettes in Exhibit 1 since they are central to this 







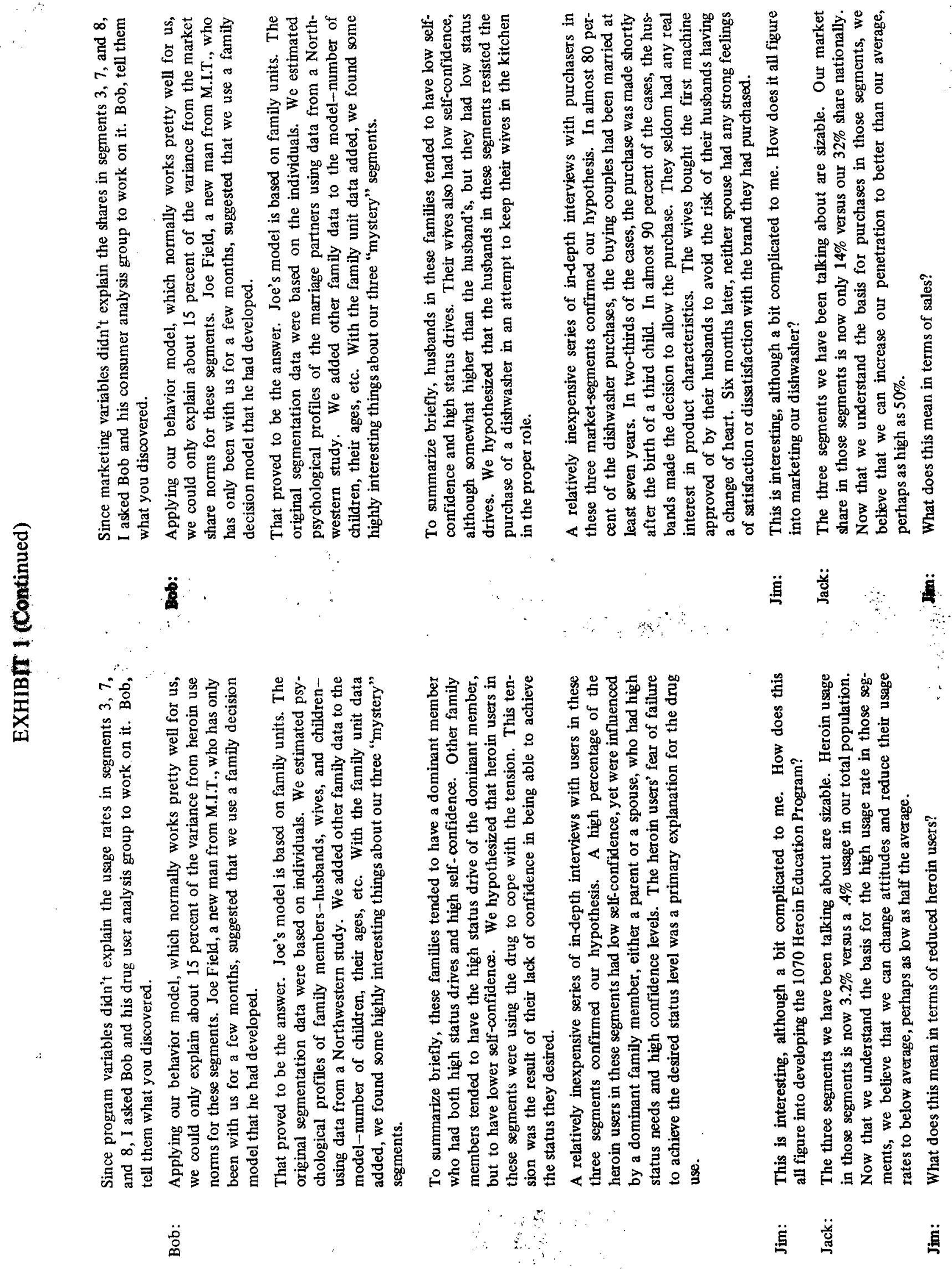




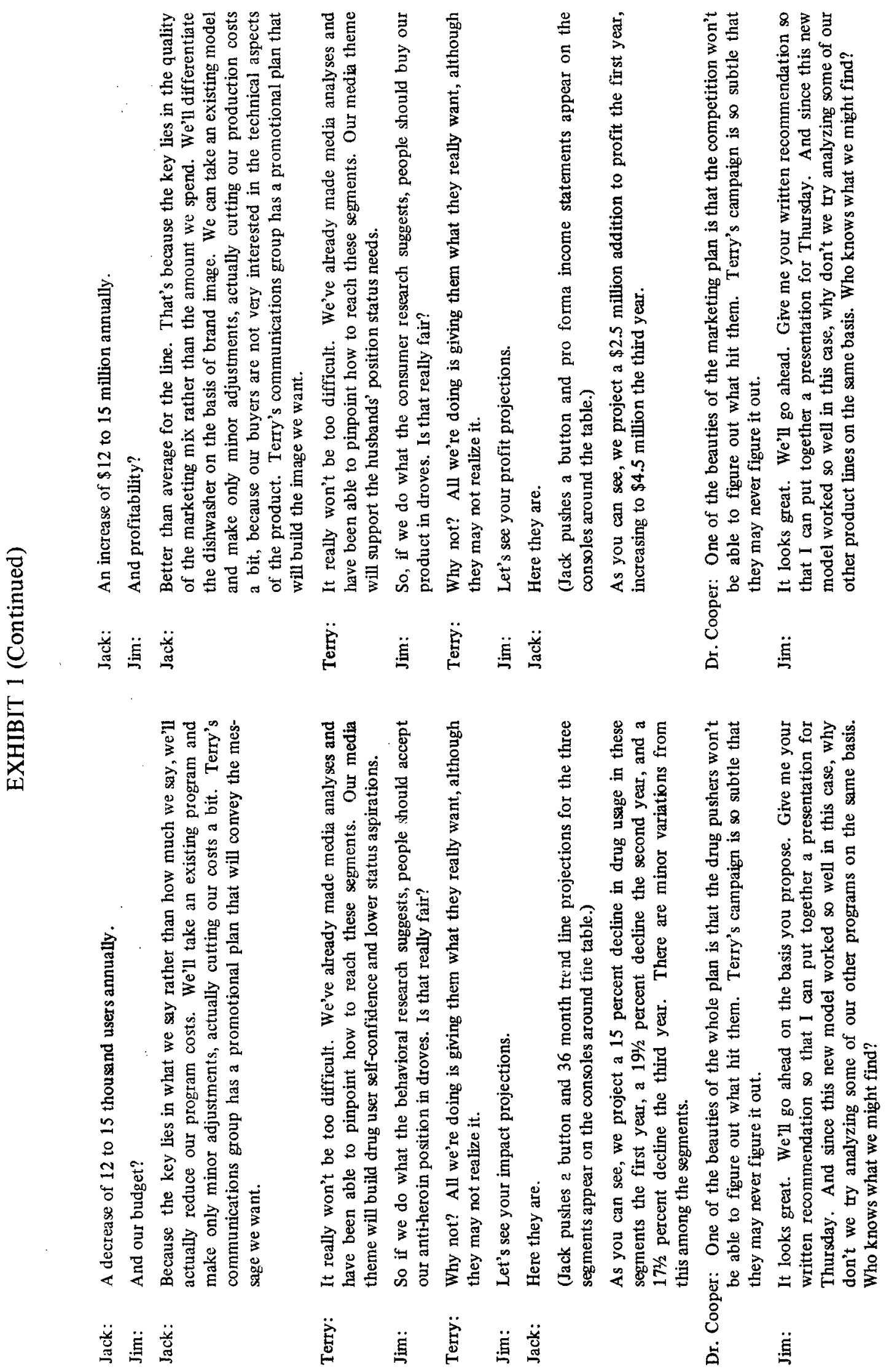


research method). ${ }^{1}$ The authors hypothesized that despite comparable marketing campaigns, the application of marketing techniques to each of the products would be perceived as having different degrees of ethical propriety.

The sample of respondents consisted of $259 \mathrm{MBA}$ candidates from three U.S. universities. The authors considered a mail survey to distribute the vignettes to a larger sample of businessmen, but rejected this option because it would distract from the control of the design (by varying the administration conditions of the instrument and by nonresponse). The authors also considered sampling members of the general public, but rejected this alternative because of the specialized jargon used for purposes of realism in the vignettes. Since the MBA sample included many practicing business executives (the students averaged 3.8 years of management experience), the authors believed the group to be particularly sensitive to the intricacies of conducting a marketing campaign. Since business students might be expected to be more sympathetic to the application of marketing to various situations than members of the public at large, it was also believed that the sample would provide a stern test of the proposition that the ethical propriety of marketing was product dependent.

A completely randomized fixed-effects experimental design was implemented with the four different product vignettes used as the treatment levels. Subjects were randomly assigned a treatment level. After reading the vignette, the subjects were asked to respond to the follow ing statement on a five-point response scale (1=strongly agree, $5=$ strongly disagree):

The application of marketing techniques to marketing problems as in the manner described is ethically wrong.

To provide an additional related measure, they were asked to respond on an identical scale to the following statement as well:

The application of marketing techniques to marketing problems as in the manner described is not a managerially responsible action for management to take.

Therefore, the hypotheses under investigation were:

(a) The degree of agreement with the statement "the application of marketing techniques to marketing problems as in the manner described is ethically wrong" is dependent upon the economic or social good being marketed.

\footnotetext{
$1_{\text {Because of their specialized nature, pretesting of the vignettes }}$ was limited to the evaluations of our colleagues. It should be noted that the vignettes contain slight differences in terminology. The two sample vignettes presented are representative of the minor differences contained, and the authors believe that after examination most readers will find them to be parallel and consistent.
}

(b) The degree of agreement with the statement "the application of marketing techniques to marketing problems in the manner described is not a managerially responsible action for management to take" is dependent upon the economic or social good being marketed.

The nonparametric Kruskal-Wallis 1-way ANOVA was used to analyze the responses. The technique assumes no underlying distribution of responses and can handle ordinal data (Conover 1971, p. 256).

\section{RESULTS AND DISCUSSION}

Both hypotheses were accepted at the .01 level of significance (see Table 1). That is, the distribution of responses for each product treatment was significantly different. Thus, there is initial evidence that the product involved in the scenario influenced the subject's response. This occurred despite the fact that (a) the marketing process described in each vignette is identical except for the product involved and (b) the subjects are asked to judge the appropriateness of the marketing techniques (process) rather than evaluating the product involved.

While the 1-way ANOVA indicates there was a difference in treatment levels, it does not pinpoint where the differences among the product levels occur. Thus additional ex post facto analysis, also using Kruskal-Wallis 1-way ANOVA was performed. 2 The analysis revealed the following:

The groups receiving the political candidate or drug education treatments vs. the groups receiving the dishwasher or hot lather treatment are in more agreement with the statements that: (1) "the application of marketing techniques to marketing problems as in the manner described is ethically wrong" and (2) "the application of marketing techniques to marketing problems as in the manner described is not a managerially responsible action for management to take." (See Table 2)

\footnotetext{
2 There have been a variety of statistical tests developed to perform ex post facto analysis in a one-way ANOVA. These tests include Fisher's LSD, Turkey's HSD, Scheffe's S Method, NewmanKeuls Test, and Ducan's New Multiple Range Test. Unfortunately, all of these tests assume parametric data. As we mentioned previously, the data at hand is ordinal in nature and non-normal. The important point to recognize however, is that all of these tests attempt to prevent the researcher from claiming a certain degree of statistical significance, when in fact, the amount of data "snooping" insures that some significance will be found. In the case at hand, only two ex post facto comparisons were made and each was found to be significant at the .01 level. Furthermore, for the entire study, only four statistical tests were performed. Therefore, although the actual expected errors in our experiment may exceed .01 , these are definitely not in excess of .04 .
} 
TABLE 1

STATISTICAL RESULTS OF A PRIORI HYPOTHESES TESTS*

\begin{tabular}{|c|c|c|c|c|c|}
\hline \multirow[t]{2}{*}{ STATEMENT } & \multicolumn{4}{|c|}{ TREATMENT } & \multirow{2}{*}{$\begin{array}{l}\text { SIGNIFICANCE } \\
\text { LEVEL }\end{array}$} \\
\hline & $\begin{array}{l}\text { Political } \\
\text { Candidate } \\
(\mathrm{N}=62)\end{array}$ & $\begin{array}{l}\text { Drug } \\
\text { Education } \\
(\mathrm{N}=67)\end{array}$ & $\begin{array}{l}\text { Dishwasher } \\
(\mathrm{N}=63)\end{array}$ & $\begin{array}{l}\text { Hot Lather } \\
\text { Machine } \\
(\mathrm{N}=61)\end{array}$ & \\
\hline $\begin{array}{l}\text { The application of marketing techniques } \\
\text { to marketing problems as in the manner } \\
\text { described is ethically wrong. }\end{array}$ & $115.81^{*}$ & 111.86 & 149.93 & 131.32 & .007 \\
\hline $\begin{array}{l}\text { The application of marketing techniques } \\
\text { to marketing problems as in the manner } \\
\text { described is not a managerially responsi- } \\
\text { ble action for management to take. }\end{array}$ & 111.94 & 110.78 & 137.15 & 149.65 & .001 \\
\hline
\end{tabular}

*Kruskal-Wallis 1-way ANOVA. Numbers in table represent mean ranks.

All subjects from the four treatment groups are rank-ordered in a single series based upon their response to each statement. For each group, the ranks are summed and divided by the sample size of each group to obtain a mean rank. It is these mean ranks that are reported in the Table. Note that a larger mean rank is associated with a higher average response to the question under investigation.

TABLE 2

STATISTICAL RESULTS OF EX POST FACTO HYPOTHESIS TESTS*

\begin{tabular}{|c|c|c|c|}
\hline \multirow[t]{2}{*}{ STATEMENT } & \multicolumn{2}{|c|}{ TREATMENT } & \multirow{2}{*}{$\begin{array}{l}\text { SIGNIFICANCE } \\
\text { LEVEL }\end{array}$} \\
\hline & $\begin{array}{l}\text { Political \& } \\
\text { Drug } \\
(\mathrm{N}=129)\end{array}$ & $\begin{array}{c}\text { Dishwasher \& } \\
\text { Hot Lather Machine } \\
(\mathrm{N}=124)\end{array}$ & \\
\hline $\begin{array}{l}\text { The application of marketing techniques } \\
\text { to marketing problems as in the manner } \\
\text { described is ethically wrong. }\end{array}$ & $113.76^{*}$ & 140.77 & .002 \\
\hline $\begin{array}{l}\text { The application of marketing techniques } \\
\text { to marketing problems as in the manner } \\
\text { described is not a managerially responsible } \\
\text { action for management to take. }\end{array}$ & 111.33 & 143.30 & .000 \\
\hline
\end{tabular}

*Kruskal-Wallis 1-way ANOVA. Numbers in table represent mean ranks.

All subjects from the four treatment groups are rank-ordered in a single series based upon their response to each statement. For each group, the ranks are summed and divided by the sample size of each group to obtain a mean rank. It is these mean ranks that are reported in the Table. Note that a larger mean rank is associated with a higher average response to the question under investigation. 
This is somewhat surprising. Why would a program as seemingly beneficial as the marketing of drug education be viewed as tending toward being unethical and managerially irresponsible? Why would the marketing of "hot lather" machines be relatively unquestioned from an ethical standpoint? Possibly because subjects were making a distinction between social products and economic products. That is, the sophisticated application of marketing techniques to economic commodities is relatively familiar and acceptable to most businessmen and members of the general public. Most persons have come to expect a certain amount of persuasion to be present in attempts to sell economic commodities. However, with the application of advanced marketing techniques to social issues (i.e., social products), it is quite possible that the subjects become somewhat uncomfortable. As one respondent put it (reacting to the marketing campaign for drug education), "Helping others for their own good sounds nice, but I have a great distrust for anyone deciding who and what help to give." Another subject, referring to the political candidate scenarios commented, "The implications of such blatant psychological manipulation are frightening."

It should be quickly added that the respondents, on the average, disagreed with the statement "the application of marketing techniques to marketing problems in the manner described is ethically wrong" for all treatment levels (see Table 3). Similarly, the subjects disagreed, on the average, that such marketing campaigns were "not managerially responsible." Nevertheless, the disagreement to these statements was mild in the case of the drug education program and the political candidate and much stronger in the case of the hot lather machines and the dishwasher (Table 3). Put another way, subjects were fairly sure that the application of sophisticated marketing techniques to dishwashers and hot lather machines was ethical and managerially responsible. Subjects were significantly less certain about the application of similar marketing strategy to political candidates and drug education. Yet, on the whole, all of the scenarios were viewed as ethical by the subjects. Again, perhaps this is due to the nature of the participants-MBA candidates. Current and future managers might be expected to be sympathetic to the necessity of using every means possible to successfully market a product or disseminate an idea.

\section{CONCLUSIONS AND IMPLICATIONS}

The preceding analysis culminates in the following: First, a group as sympathetic to management as MBA candidates, implies by its responses that the nature of the product involved will change its ethical evaluation concerning the propriety of a marketing campaign. Second, it appears that future managers (MBA candidates) are more uncertain about the ethical propriety of marketing social ideas (products) than traditional economic goods. Third, marketing campaigns for social products are viewed as tending to be less "managerially responsible" than marketing campaigns for traditional economic goods. Fourth, all the vignettes were, on the average, perceived as ethical marketing campaigns, although those involving a political candidate and a drug education program were seen as such by a narrow margin.

Taken collectively the sample evidence implies that current and future managers, in their evaluations of several similar marketing campaigns are in fact influenced by the product being marketed. It is quite possible that, as marketing professionals become involved in campaigns for

TABLE 3

MEAN SCALE RESPONSE TO STATEMENTS*

\begin{tabular}{|c|c|c|c|c|}
\hline \multirow[t]{2}{*}{ STATEMENT } & \multicolumn{4}{|c|}{ TREATMENT } \\
\hline & $\begin{array}{l}\text { Political } \\
\text { Candidate } \\
(\mathrm{N}=62)\end{array}$ & $\begin{array}{c}\text { Drug } \\
\text { Education } \\
(\mathrm{N}=67)\end{array}$ & $\begin{array}{c}\text { Dishwasher } \\
(\mathrm{N}=63)\end{array}$ & $\begin{array}{c}\text { Hot Lather } \\
\text { Machine } \\
(\mathrm{N}=61)\end{array}$ \\
\hline
\end{tabular}

The application of marketing techniques to marketing problems as in the manner described is ethically wrong.

The application of marketing techniques to marketing problems as in the manner described is not a managerially responsible action for management to take.

*Where 1 =strongly agree, $5=$ strongly disagree. 
certain controversial social products such as political candidates, Equal Rights Legislation, or Beverage Container Regulations to name but a few, marketers may come under increasing public attack. They may be accused by segments of the public as being "manipulators," "propagandists," or "hidden persuaders." Significantly, the criticism may come not because people object to the marketing campaign which has been created, but because they ethically or morally oppose the issue or product which is being promoted. This study deals with MBA candidates-a student sample. In addition, it examines reactions to only four products-two economic goods and two social goods. Therefore, more elaborate research is called for. Logically, the next study utilizing the vignette method to analyze these issues should be conducted using consumers in general and perhaps consumerist critics in particular. Ideally, more product categories should be involved, although including similar products to those evaluated in this study, would partially test the reliability of the findings contained in this research. That fact that MBA candidates were as relatively critical concerning the ethical implications of marketing practices as the data indicated came as a surprise to the authors. The social significance of this finding needs to be pondered as well as validated in subsequent studies. However, if the public reacts similarly to this sample, the involvement of marketing professionals in areas relating to social products should be undertaken with caution.

A second point might be noted. It is inevitable that marketing professionals will become involved in many new social areas. Vignettes similar to those used in this research may be used fruitfully to anticipate public reaction to contemplated social marketing campaigns. In any event, it seems likely that if the public negatively reacts to fullscale marketing campaigns for certain social products, this may pave the way for additional restrictions upon other product categories and their marketing strategies. It seems logical that once regulations are in place covering certain categories of social products, they may facilitate experimentation with these forms of regulations over traditional economic products. Most important, this domino effect of restriction could occur despite the fact that the process of marketing is being executed legally. Thus, professional marketers should move judiciously when requested to conduct marketing campaigns for controversial social products. Lack of caution could lead to increased criticism and regulation for the entire marketing profession.

\section{REFERENCES}

Alexander, Cheryl S., and Henry Jay Becker (1978), "The Use of Vignettes in Survey Research," Public Opinion Quarterly, (Spring), 93-104.

Andreason, Alan R., and Arthur Best (1977), "Consumers Complain-Does Business Respond?" Harvard Business Review, (July-August), 93-103.

Calihan, William J., Jr. (1967), "Ethics in Today's Marketing," in Changing Marketing Systems, R. Moyer, ed., Chicago: American Marketing Association.

Clausen, Earl A. (1967), "Marketing Ethics and the Consumer," Harvard Business Review, (JanuaryFebruary), 79-86.

Conover, W. J. (1971), Practical Nonparametric Statistics, New York: John Wiley and Sons, Inc.

Gaedeke, Ralph M., ed. (1977), Marketing in Private and Nonprofit Organizations: Perspectives and Illustrations, Santa Monica, California: Goodyear Publishing, Inc.

Greenland, Leo (1974), "Advertisers Must Stop Conning Consumers," Harvard Business Review, (July-August), 18-28.

Hise, Richard T., and Michael A. McGinnis (1975), "Product Elimination: Practices, Policies and Ethics," Business Horizons, (June), 25-32.

Kotler, Philip (1975), Marketing For Nonprofit Organizations, Englewood Cliffs, NJ: Prentice-Hall, Inc. , and Sidney J. Levy (1969), "Broadening the Concept of Marketing," Journal of Marketing, (January), 10-15.

, and Gerald Zaltman (1971), "Social Marketing: An Approach to Planned Social Change," Journal of Marketing, (July), 3-12.

Laczniak, Gene R., Robert F. Lusch, and Patrick E. Murphy (1979), "Social Marketing: Its Ethical Dimension," Journal of Marketing, (Spring), 29-36.

Nosanchuk, T. A. (1972), "The Vignette As An Experimental Approach To the Study of Social Status: An Exploratory Study," Social Science Research, Vol. I, No. 1 (April), 107-120.

Rossi, Peter H., William A. Simpson, and Christine E. Bose (1974), "Measuring Household Social Standing," Social Science Research, Vol. III, No. 3 (September), 169-190. 